\title{
Cobalt oxide nanoparticle-modified carbon nanotubes as an electrocatalysts for electrocatalytic evolution of oxygen gas
}

\author{
JAHAN BAKHSH RAOOF ${ }^{1, *}$, FERESHTEH CHEKIN ${ }^{2}$ and VAHID EHSANI ${ }^{1}$ \\ ${ }^{1}$ Electroanalytical Chemistry Research Laboratory, Faculty of Chemistry, Department of Analytical Chemistry, \\ Mazandaran University, Babolsar, Iran \\ ${ }^{2}$ Ayatollah Amoli Branch, Department of Chemistry, Islamic Azad University, PO Box 678, Amol, Iran
}

MS received 13 September 2013; revised 18 November 2013

\begin{abstract}
A simple procedure was developed to prepare cobalt oxide nanoparticles (nano- $\mathrm{CoO}_{\mathrm{x}}$ ) on multiwall carbon nanotube-modified glassy carbon electrode (MWNT/GCE). Scanning electron microscopy revealed the electrodeposition of nano- $\mathrm{CoO}_{\mathrm{x}}$ with an average particle size of $25 \mathrm{~nm}$ onto MWNT/GCE. Also, the presence of nano- $\mathrm{CoO}_{x}$ was revealed by energy dispersive $\mathrm{X}$-ray spectra. The electrocatalytic activity of nano-CoO $\mathrm{O}_{\mathrm{x}}$ and $\mathrm{MWNT}$ composite-modified GCE $\left(\mathrm{CoO}_{\mathrm{x}}-\mathrm{MWNT} / \mathrm{GCE}\right)$ has been examined towards the oxygen evolution reaction (OER) by linear sweep voltammetry. The OER is significantly enhanced at $\mathrm{CoO}_{\mathrm{x}}-\mathrm{MWNT/GCE}$, as demonstrated by a negative shift in the polarization curves at the $\mathrm{CoO}_{\mathrm{x}}-\mathrm{MWNT} / \mathrm{GCE}$ compared with that obtained at the $\mathrm{CoO}_{\mathrm{x}}-\mathrm{GCE}$ and GCE. Optimization of the operating experimental conditions (i.e., solution pH and loading level of nano-CoO $\mathrm{C}_{\mathrm{x}}$ ) has been achieved to maximize the electrocatalytic activity of $\mathrm{CoO}_{\mathrm{x}}-\mathrm{MWNT/GCE}$. The maximum electrocatalytic activity towards the OER was obtained in alkaline media $(\mathrm{pH}=13)$. The electrocatalytic activity of $\mathrm{CoO}_{\mathrm{x}}-\mathrm{MWNT} / \mathrm{GCE}$ increased with the number of potential cycles employed for the $\mathrm{CoO}_{\mathrm{x}}$ deposition till a certain loading (20 cycles) beyond which an adverse effect is observed. The fabricated $\mathrm{CoO}_{\mathrm{x}}-\mathrm{MWNT} / \mathrm{GCE}$ exhibited a good stability and durability. The value of energy saving per gram of oxygen gas at a current density of $10 \mathrm{~mA} \mathrm{~cm}-2$ is $19.3 \mathrm{kWh} \mathrm{kg}^{-1}$.
\end{abstract}

Keywords. Cobalt oxide nanoparticles; oxygen evolution reaction; multiwall carbon nanotubes; electrolysis.

\section{Introduction}

Recently, mediator nanomaterials on an electrode as a catalyst to develop electrochemical sensor is a hot topic owing to their large specific surface area, excellent conductivity and catalytic activity. ${ }^{1-8}$ Nanomaterials can be directly used as electrode materials or as catalytic labels for the amplified electrochemical detection. ${ }^{9}$ Among numerous nanomaterials, cobalt (Co)-based nanomaterials have attracted a considerable interest because of its good electroactivity and low cost. $^{10-13}$ For example, the Co hexacyanoferrate nanoparticles (NPs)-carbon nanotube-chitosan can be used to prepare a glucose sensor. ${ }^{14} \mathrm{Pt}-\mathrm{Co}$ NPs supported on single-walled carbon nanotubes (SWCNTs) have been applied in methanol sensing. ${ }^{15}$ Co NPs integrated with SWCNTs have been employed for sensitive detection of nitrite. ${ }^{16}$ Cobalt oxidebased nanomaterials, in particular, are used for the production of magneto-resistive devices, ${ }^{17}$ electrochoromic thin films, ${ }^{18}$ energy storage systems, ${ }^{19}$ heterogeneous catalysts ${ }^{20}$ and electrocatalysis. ${ }^{21}$ Electrochemical deposition is an economical and convenient choice for preparing uniform and size controllable nanomaterials, ${ }^{22}$ especially the preparation of metallic nanomaterials..$^{23,24}$

The oxygen evolution reaction (OER) attracts a reasonable deal of attention as a consequence of its importance

\footnotetext{
*Author for correspondence (j.raoof@umz.ac.ir)
}

in a wide range of industrial applications, such as water electrolysis, energy conversion and storage devices. ${ }^{25-30}$ There is an extensive work in the literature addressing the development and characterization of suitable anodic materials for the applications in water electrolysis and batteries technology. ${ }^{31-33}$ As alternative to precious metals, metal oxide-based electrodes, particularly Ni and Co oxides, have long been used as electrocatalysts for the OER in alkaline electrolyzers due to their great stability and high activity. ${ }^{27,34-37}$

In this study, the modification of glassy carbon (GC) and multiwall carbon nanotube-modified glassy carbon (MWNT/GC) electrodes with nano-structured Co oxide (nano- $\mathrm{CoO}_{\mathrm{x}}$ ) results in a significant enhancement in the electrocatalytic activity towards the OER. The effect of $\mathrm{pH}$ of the electrolyte and the effect of loading level of the electrocatalysts on the electrocatalytic activity have been investigated.

\section{Experimental}

\subsection{Chemicals and apparatus}

Cobalt nitrate and potassium hydroxide were purchased from Aldrich. Carbon nanotubes (outer diameter: 20-40 nm, length: 5-15 $\mu \mathrm{m}$, purity > 97) were purchased from Shenzhen Nano-Technologies Port Co., Ltd (China) and were purified 

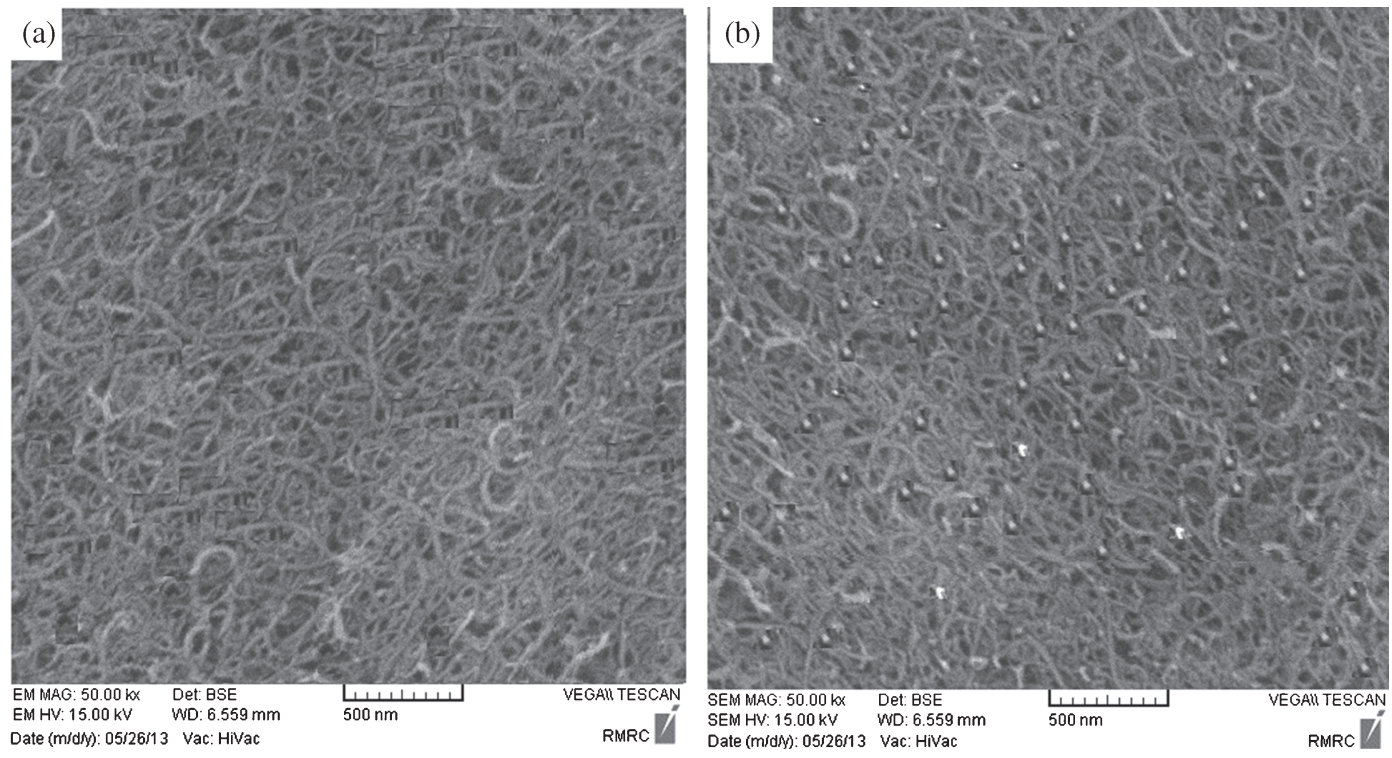

Figure 1. SEM image of (a) MWNT/GCE and (b) $\mathrm{CoO}_{\mathrm{x}}-\mathrm{MWNT} / \mathrm{GCE}$.

using a mixture of sulphuric acid and nitric acid in a composition of $3 / 2$ by volume. Electrochemical measurements were performed with an Autolab Potentiostat/Galvanostat (The Netherlands). The three-electrode system consists of $\mathrm{CoO}_{\mathrm{x}}-\mathrm{MWNT} / \mathrm{GCE}, \mathrm{CoO}_{\mathrm{x}} / \mathrm{GCE}$ and GCE as working electrodes, $\mathrm{Ag}|\mathrm{AgCl}| \mathrm{KCl}_{3 \mathrm{M}}$ as the reference electrode and a platinum wire as an auxiliary electrode (Metrohm) were used in all voltammetric experiments. Hitachi S-3500N scanning electron microscope (SEM) with energy dispersive X-ray (EDAX) spectroscopy was used for surface image measurements and chemical characterization of a specimen.

\subsection{Preparation of $\mathrm{CoO}_{x}-\mathrm{MWNT/GCE}$}

Appropriate amount of MWNTs were dispersed in $1 \mathrm{ml}$ dimethyl formamide with the aid of ultrasonic agitation for $20 \mathrm{~min}$. Prior to use, the $\mathrm{GC}$ electrode (diameter $1.8 \mathrm{~mm}$ ) was first polished with alumina $(0.05 \mu \mathrm{m})$ slurry and ultrasonically cleaned with ethanol and double distilled water, then dried in room temperature. A quantity of $5 \mu \mathrm{l}$ of MWNT dispersed solution was coated on the GCE surface and dried in air. The fabrication of the nano- $\mathrm{CoO}_{\mathrm{x}}$ on the MWNT/GCE surface was carried out by the cyclic voltammetry technique. Typically, the potential was scanned for 20 potential cycles with a scan rate of $100 \mathrm{mV} \mathrm{s}^{-1}$ in the potential range between -0.7 and $0.8 \mathrm{~V}$ vs. $\mathrm{Ag}|\mathrm{AgCl}| \mathrm{KCl}_{3 \mathrm{M}}$ in phosphate buffer solution $(\mathrm{pH}=7)$ containing $1 \mathrm{mM}$ cobalt nitrate.

\section{Results and discussions}

\subsection{Characterization of $\mathrm{CoO}_{x}-M W N T / G C E$}

Figure 1 shows the SEM images of MWNT/GCE and $\mathrm{CoO}_{\mathrm{x}}-$ MWNT/GCE. The SEM images reveal that cobalt oxide

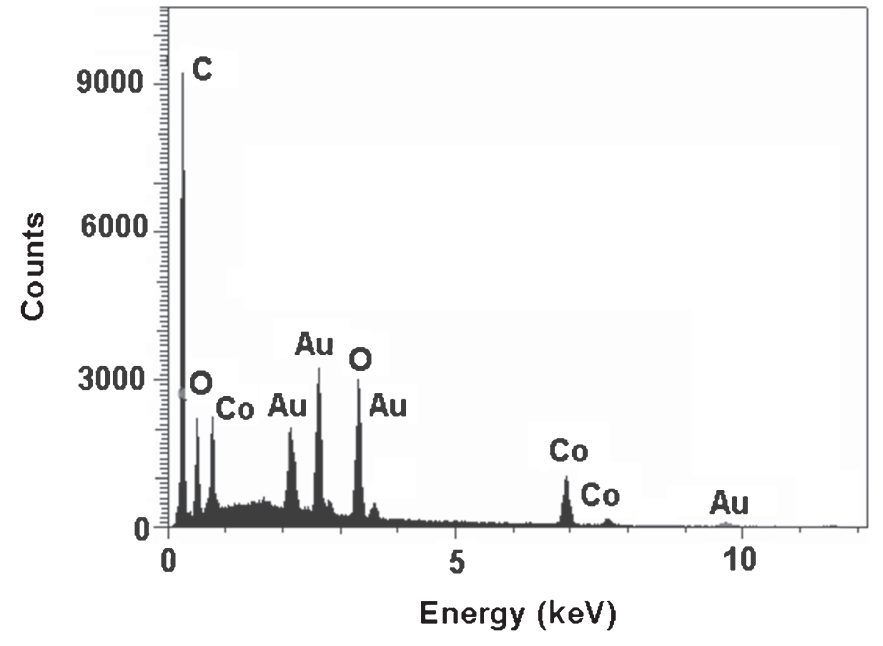

Figure 2. EDAX pattern of $\mathrm{CoO}_{\mathrm{x}}-\mathrm{MWNT} / \mathrm{GCE}$.

particles with average size of about $25 \mathrm{~nm}$ distributed on the surface of MWNT modified electrode. After the electrochemical modification step, EDAX spectra were carried out at nano- $\mathrm{CoO}_{\mathrm{x}}$-modified MWNT/GC electrode and the corresponding results are shown in figure 2. Inspection of this figure indicates the presence of $\mathrm{C}, \mathrm{Co}$ and $\mathrm{O}$ elements at the electrode surface indicating formation of nano- $\mathrm{CoO}_{\mathrm{x}}$.

\subsection{Electrochemical properties of nano-CoO $O_{x}$ deposited on MWNT/GC electrode}

Figure 3 shows a cyclic voltammograms of the modified electrodes in $0.5 \mathrm{M} \mathrm{KOH}$ solution in the potential window of -100 to $400 \mathrm{mV}$ with a potential sweep rate of $100 \mathrm{mV} \mathrm{s}^{-1}$. As shown, at $\mathrm{CoO}_{\mathrm{x}}-\mathrm{MWNT} / \mathrm{GCE}$ (curve b) in comparison to $\mathrm{CoO}_{\mathrm{x}}-\mathrm{GCE}$ (curve a), the anodic and cathodic peaks shift 

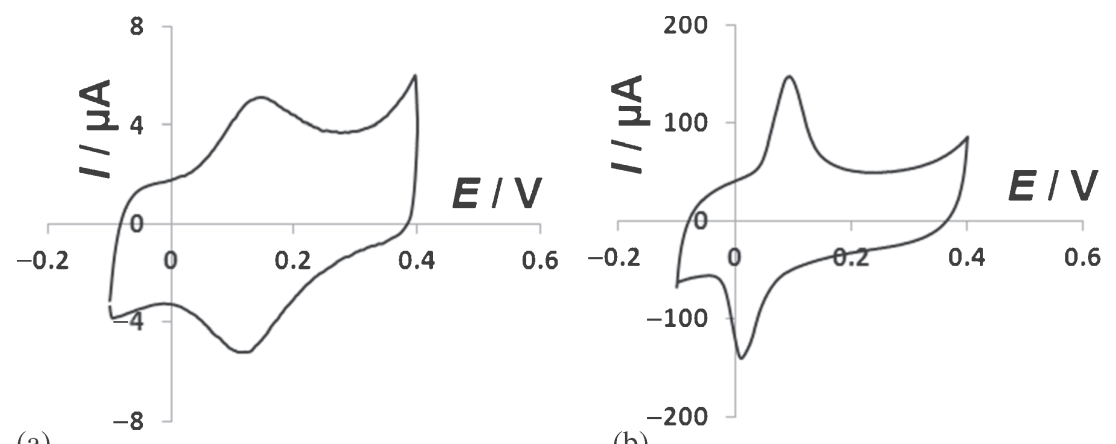

(a)

(b)

Figure 3. Cyclic voltammograms of (a) $\mathrm{CoO}_{x}-\mathrm{GCE}$ and (b) $\mathrm{CoO}_{\mathrm{x}}-\mathrm{MWNT} / \mathrm{GCE}$ in $0.5 \mathrm{M} \mathrm{KOH}$ at potential scan rate of $100 \mathrm{mV} \mathrm{s}^{-1}$.

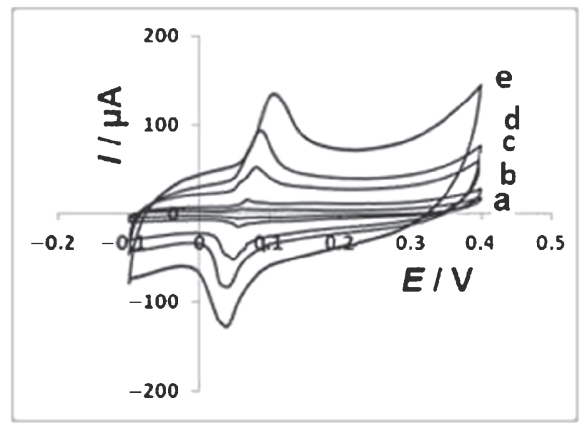

(a)

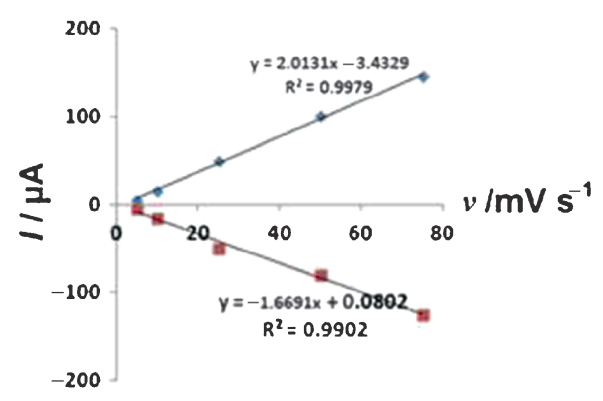

(b)

Figure 4. (A) Cyclic voltammograms of $\mathrm{CoO}_{\mathrm{x}}-\mathrm{MWNT} / \mathrm{GCE}$ in $0.5 \mathrm{M} \mathrm{KOH}$ solution at different scan rates. The scan rates are: (a) 5 , (b) 10 , (c) 25 , (d) 50 and (e) $75 \mathrm{mV} \mathrm{s}^{-1}$, respectively. (B) The plot of cathodic and anodic peak currents $v$ s. scan rates.

towards less positive potentials with an increase in the oxidation and reduction peak current. The increase in peak current results from MWNT, due to high specific surface area, uniform-ordered porous structure and suitable pore size, played an important role in facilitating the electron transfer between the nano- $\mathrm{CoO}_{\mathrm{x}}$ and GCE.

A couple of reversible and defined peaks with the apparent formal peak potential $\left(E^{\circ}\right)$ of $60 \mathrm{mV}$ were observed at $100 \mathrm{mV} \mathrm{s}^{-1}$ for $\mathrm{CoO}_{\mathrm{x}}-\mathrm{MWNT/GCE}$. An anodic peak at $100 \mathrm{mV}$ attributed to $\mathrm{Co}$ (II)/Co(III) redox transition associated with the electrode surface. The cathodic peak at $20 \mathrm{mV}$ correspond to the reduction of various cobalt oxide species formed during the anodic sweep. The stability of the modified electrode was checked by consecutive cyclic voltammograms of $\mathrm{CoO}_{\mathrm{x}}-\mathrm{MWNT} / \mathrm{GCE}$ electrode in $0.5 \mathrm{M} \mathrm{KOH}$. For the $\mathrm{CoO}_{\mathrm{x}}-$ MWNT composite almost no activity variation was observed even after 30 cycles, indicating its stability in $\mathrm{KOH}$ medium.

The redox potential of the $\mathrm{CoO}_{\mathrm{x}}-\mathrm{MWNT} / \mathrm{GCE}$ is scan rate dependent. Figure $4 \mathrm{a}$ shows the cyclic voltammograms of the $\mathrm{CoO}_{\mathrm{x}}-\mathrm{MWNT} / \mathrm{GCE}$ in $0.5 \mathrm{M} \mathrm{KOH}$ at various scan rates. It was observed that the values of $E_{\mathrm{pa}}$ and $E_{\mathrm{pc}}$ shift slightly to the positive and negative directions, respectively, and $\Delta E_{\mathrm{p}}$ increases with increasing scan rate. The anodic and cathodic peak currents are linearly proportional to scan rate (figure 4b), suggesting that the reaction is not a diffusioncontrolled process but a surface-controlled one.
A plot of $E_{\mathrm{p}} v s . \log v$ yields straight line with slopes of $-2.3 R T / a n F$ and $2.3 R T /(1-a) n F$ for the cathodic and anodic peak, respectively, so that $a$ can be estimated as 0.51 from the slope of the straight lines. The surface concentration of the electroactive nano- $\mathrm{CoO}_{\mathrm{x}}$ on $\mathrm{CoO}_{\mathrm{x}}-\mathrm{MWNT} / \mathrm{GCE}$, $\Gamma$ (in $\mathrm{mol} \mathrm{cm}^{-2}$ ), can be estimated by below equation: ${ }^{38}$

$$
\Gamma=Q / n F A,
$$

where $Q$ is the charge consumed in coulombs, obtained from integrating the anodic (or cathodic) peak area in cyclic voltammograms under the background correction, $A$ is the electrode surface geometrical area $\left(0.025 \mathrm{~cm}^{2}\right), n$ represents the number of electrons involved in reaction $(n=1)$ and $F$ is Faraday constant $\left(F=96493 \mathrm{C} \mathrm{mol}^{-1}\right)$. The average $\Gamma$ value of $6.22 \times 10^{-10} \mathrm{~mol} \mathrm{~cm}^{-2}$ was obtained.

\subsection{Electrocatalytic behaviour of $\mathrm{CoO}_{x}-M W N T / G C E$}

Previous reports showed that nano- $\mathrm{CoO}_{\mathrm{x}}$-modified electrodes could display an electrochemical response towards the OER. ${ }^{36,37}$ Here, the electro-catalytic activity of $\mathrm{CoO}_{\mathrm{x}}-$ MWNT/GCE in OER was also observed. As it is seen from figure 5, linear sweep voltammograms (LSVs) obtained for bare GCE, $\mathrm{CoO}_{\mathrm{x}}-\mathrm{GCE}$ and $\mathrm{CoO}_{\mathrm{x}}-\mathrm{MWNT} / \mathrm{GCE}$ in $0.5 \mathrm{M} \mathrm{KOH}$, the OER at bare GCE requires very high 
positive potentials, leading to a poorly defined anodic wave involving very slow electrode kinetics. In contrast, OER at the $\mathrm{CoO}_{\mathrm{x}}-\mathrm{GCE}$ and $\mathrm{CoO}_{\mathrm{x}}-\mathrm{MWNT} / \mathrm{GCE}$ in $0.5 \mathrm{M} \mathrm{KOH}$ occurred at much less positive potentials with an increase in current density. Also, a significant decrease of potential at a current density of $20 \mathrm{~mA} \mathrm{~cm}{ }^{-2}\left(E_{20}\right)$ at the $\mathrm{CoO}_{\mathrm{x}}-\mathrm{GCE}$ $(0.73 \mathrm{~V})$ and $\mathrm{CoO}_{\mathrm{x}}-\mathrm{MWNT} / \mathrm{GCE}(0.70 \mathrm{~V})$ compared with GCE ( $>1.50)$ was observed. This indicates a significant enhancing role of the nano- $\mathrm{CoO}_{\mathrm{x}}$ towards the OER. This corresponds to an equivalent decrease in the energy consumption accompanying the overall electrolysis process.

In order to express potential in terms of the oxygen overpotential, $\eta$ (when the reference electrode is $\mathrm{Ag} / \mathrm{AgCl}$ electrode) can be estimated using the equation: ${ }^{36,37}$

$$
\eta=E_{\text {meas }}-0.207 \mathrm{~V},
$$

where, $E_{\text {meas }}$ is the measured electrode potential for the OER.

Table 1 lists the oxygen evolution of overpotentials $(\eta)$ at the GCE, $\mathrm{CoO}_{\mathrm{x}}-\mathrm{GCE}$ and $\mathrm{CoO}_{\mathrm{x}}-\mathrm{MWNT} / \mathrm{GCE}$ in $0.5 \mathrm{M}$ $\mathrm{KOH}$ at various current densities. There is a variation of the values of $\eta$ at the three substrates, at the same current density. What is also seen is that the overpotentials are lower on $\mathrm{CoO}_{\mathrm{x}}-\mathrm{MWNT}$-modified GCE than on the $\mathrm{CoO}_{\mathrm{x}}-\mathrm{MWNT}-$ modified GCE. This might be attributed to great stability and high activity of nano- $\mathrm{CoO}_{\mathrm{x}}$ electrocatalys at the surface MWNT/GCE for the OER.

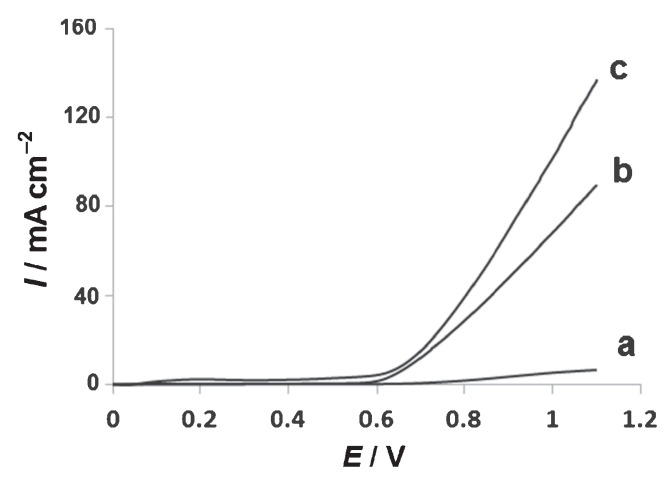

Figure 5. LSV response for the OER in $0.5 \mathrm{M} \mathrm{KOH}$ at the (a) GCE, (b) $\mathrm{CoO}_{\mathrm{x}}-\mathrm{GCE}$ and (c) $\mathrm{CoO}_{\mathrm{x}}-\mathrm{MWNT} / \mathrm{GCE}$ at potential scan rate of $100 \mathrm{mV} \mathrm{s}^{-1}$.

Table 1. Oxygen evolution overpotential at modified electrodes in $0.5 \mathrm{M} \mathrm{KOH}$ at different current densities.

\begin{tabular}{lccc}
\hline & \multicolumn{3}{c}{$\eta / \mathrm{mV}$} \\
\cline { 2 - 4 }$I / \mathrm{mA} \mathrm{cm}^{-2}$ & GCE & $\mathrm{CoO}_{\mathrm{x}}-\mathrm{GCE}$ & $\mathrm{CoO}_{\mathrm{x}}-\mathrm{MWNT} / \mathrm{GCE}$ \\
\hline 10 & 895 & 493 & 473 \\
20 & - & 513 & 493 \\
30 & - & 603 & 573 \\
40 & - & 623 & 583 \\
50 & - & 643 & 593 \\
60 & - & 743 & 603 \\
\hline
\end{tabular}

\subsection{Effect of the nano-CoO loading level}

The effect of loading of the nano- $\mathrm{CoO}_{\mathrm{x}}$ on the electrocatalytic activity towards the OER is investigated to achieve the highest catalytic activity. As mentioned, $\mathrm{CoO}_{\mathrm{x}}$ was electrodeposited by a potential cycling method, the number of potential cycles was varied to control the loading level of the nano- $\mathrm{CoO}_{\mathrm{x}}$ on the MWNT/GCE. The corresponding LSVs of the OER at $\mathrm{CoO}_{\mathrm{x}}-\mathrm{MWNT} / \mathrm{GCE}$ at different number of potential cycles were recorded in $0.5 \mathrm{M} \mathrm{KOH}$ and are shown in figure 6 . The catalytic enhancement of the OER increases at the beginning with the increase in the number of potential cycles. The highest catalytic enhancement was obtained at the MWNT/GC electrode after depositing the nano- $\mathrm{CoO}_{\mathrm{x}}$ for 20 potential cycles. When the number of potential cycles increased to 50 , a significant reduction in the electrocatalytic activity was noticed.

\subsection{Effect of $\mathrm{pH}$}

The effect of solution $\mathrm{pH}$ on the electrocatalytic activity of the $\mathrm{CoO}_{\mathrm{x}}-\mathrm{MWNT} / \mathrm{GCE}$ towards the OER was examined by measuring the LSVs at the $\mathrm{CoO}_{\mathrm{x}}-\mathrm{MWNT} / \mathrm{GCE}$ at various $\mathrm{pH}$ values (figure 7). As depicted from this LSVs, the maximum

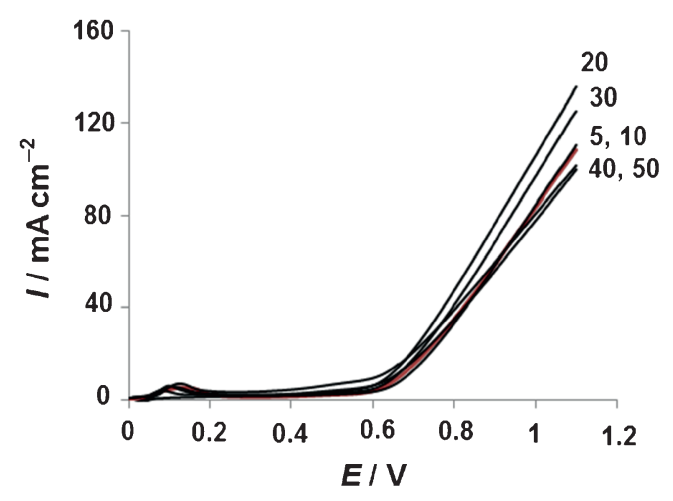

Figure 6. LSV responses of $\mathrm{CoO}_{\mathrm{x}}-\mathrm{MWNT} / \mathrm{GCE}$ at different number of potential cycles for the OER in $0.5 \mathrm{M} \mathrm{KOH}$ at potential scan rate of $100 \mathrm{mV} \mathrm{s}^{-1}$.

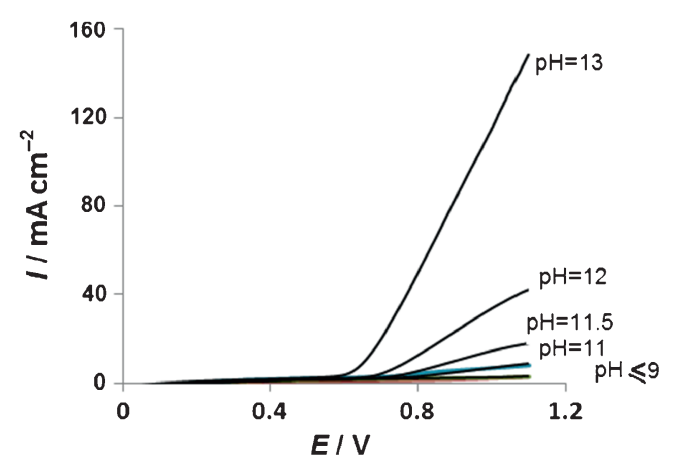

Figure 7. LSV responses of $\mathrm{CoO}_{\mathrm{x}}-\mathrm{MWNT} / \mathrm{GCE}$ for the OER in different $\mathrm{pH}$ of $\mathrm{KOH}$ solution at potential scan rate of $100 \mathrm{mV} \mathrm{s}^{-1}$. 
Table 2. The shift potential and the rate of energy saving at the anode obtained after the modification with $\mathrm{CoO}_{\mathrm{x}}-\mathrm{MWNT}$ at various current densities.

\begin{tabular}{lccccc}
\hline & \multicolumn{2}{c}{$\Delta E_{(\mathrm{a})} / \mathrm{mV}$} & & \multicolumn{2}{c}{$P_{(\mathrm{a})} / \mathrm{kWh} \mathrm{kg}^{-1}$} \\
\cline { 2 - 3 } \cline { 5 - 6 }$I / \mathrm{mA} \mathrm{cm}^{-2}$ & $\mathrm{CoO}_{\mathrm{x}}-\mathrm{GCE}$ & $\mathrm{CoO}_{\mathrm{x}}-\mathrm{MWNT} / \mathrm{GCE}$ & & $\mathrm{CoO}_{\mathrm{x}}-\mathrm{GCE}$ & $\mathrm{CoO}_{\mathrm{x}}-\mathrm{MWNT} / \mathrm{GCE}$ \\
\hline 5 & 600 & 610 & & 16.08 & 16.35 \\
10 & 700 & 720 & & 18.76 & 19.30 \\
20 & 827 & 900 & & 22.16 & 24.12 \\
\hline
\end{tabular}

current densities of the OER was obtained in alkaline solution $(\mathrm{pH}=13)$ at every current density. Stability of the active phase of $\mathrm{CoO}_{\mathrm{x}}$ decreases in the electrocatalytic activity at neutral and acidic media. These results are similar to previous observation at the nano- $\mathrm{NiO}_{\mathrm{x}}$ and nano- $\mathrm{CoO}_{\mathrm{x}}$ modified electrodes. ${ }^{36,37}$ The OER proceeds, in alkaline medium, via the following steps sequentially: ${ }^{36,37}$

$$
\begin{aligned}
& \mathrm{OH}^{-} \rightarrow(\mathrm{OH})_{\mathrm{ads}}+\mathrm{e}^{-} \\
& (\mathrm{OH})_{\mathrm{ads}}+\mathrm{OH}^{-} \rightarrow\left(\mathrm{O}^{-}\right)_{\mathrm{ads}}+\mathrm{H}_{2} \mathrm{O}, \\
& \left(\mathrm{O}^{-}\right)_{\mathrm{ads}} \rightarrow(\mathrm{O})_{\mathrm{ads}}+\mathrm{e}^{-} \\
& 2(\mathrm{O})_{\mathrm{ads}} \rightarrow \mathrm{O}_{2} \uparrow .
\end{aligned}
$$

\subsection{Energy savings}

The values of the rate of power savings of oxygen gas were calculated and are listed in table 2 . The significant decrease in the potential obtained after the modification with nano- $\mathrm{CoO}_{\mathrm{x}}$ corresponds to a reduction in the rate of energy consumption at the anode and consequently, decreases the energy consumption in the overall process. The energy saving at the anode is given by: ${ }^{36,37}$

$$
P_{(\text {a) }}=\Delta E_{(\mathrm{a})} F / 3600,
$$

Where $\Delta E_{(\text {a) }}$ is anodic potential shift at a current density and $P_{(\mathrm{a})}$ is the KWh per $\mathrm{kg}$ of oxygen gas. The values of $P_{(\mathrm{a})}$ calculated at different current densities are listed in table 2. From the data in table 2, the best energy saving of oxygen gas is obtained at $\mathrm{CoO}_{\mathrm{x}}-\mathrm{MWNT}$-modified GCE.

\section{Conclusions}

A cheap nano-sized electrocatalyst is introduced as an anode for water electrolysis. Nano- $\mathrm{CoO}_{\mathrm{x}}$ electrocatalyst is fabricated in aqueous medium by a potential cycling method. SEM image shows the formation of nano- $\mathrm{CoO}_{x}$ with average particle size of $25 \mathrm{~nm}$. The electrocatalysis of OER at modified electrodes with $\mathrm{CoO}_{\mathrm{x}}-\mathrm{MWNT}$ has been examined using LSV. The OER is significantly enhanced upon modification of the electrodes with $\mathrm{CoO}_{\mathrm{x}}-\mathrm{MWNT}$, as demonstrated by a negative shift in the LSV curves at the
$\mathrm{CoO}_{\mathrm{x}}-\mathrm{MWNT}$-modified electrodes compared to that obtained at the unmodified ones. The maximum electrocatalytic activity towards the OER is obtained in alkaline medium $(\mathrm{pH}=13)$ after depositing the nano- $\mathrm{CoO}_{\mathrm{x}}$ for 20 potential cycles to control the loading level of the nano$\mathrm{CoO}_{\mathrm{x}}$ on the MWNT/GCE. The fabricated $\mathrm{CoO}_{\mathrm{x}}-\mathrm{MWNT}-$ modified electrodes exhibited a good stability and durability as revealed from the experiments.

\section{References}

1. Cui K, Song Y, Yao Y, Huang Z and Wang L 2008 Electrochem. Commun. 10663

2. Tian J Q, Liu S and Sun X P 2010 Langmuir 2615112

3. Zheng Z Z, Zhou Y L, Li X Y, Liu S Q and Tang Z T 2011 Biosens. Bioelectron. 505860

4. Liu S Q and Tang Z Y 2010 J. Mater. Chem. 204299

5. Li X Y, Zhou Y L, Zhou Z Z, Yue X L, Dai Z F, Liu S Q and Tang Z Y 2009 Langmuir 256580

6. Niazov T, Shlyahovsky B and Willner L 2007 J. Am. Chem. Soc. 1296374

7. Bahshi L, Frasconi M, Tel-Vered R, Yehezkeli O and Willner I 2008 Anal. Chem. 808253

8. Polsky R, Gill R and Kaganovsky L 2006 Anal. Chem. 782268

9. Riskin M, Tel-Vered R and Willner I 2009 Adv. Funct. Mater. 192474

10. Villagra E, Bedioui F, Nyokong T, Canales J C, Sancy M, Paez MA, Costamagna J and Zagal J H 2008 Electrochim. Acta 534883

11. Vidotti M, Silva M R, Salvador R P, Cordobade Torresi S I and Dall'Antonia L H 2008 Electrochim. Acta $\mathbf{5 3} 4030$

12. Ding C F, Zhao F, Zhang M L and Zhang S S 2008 Bioelectrochemistry 7228

13. Arguello J, Magosso H A, Landers R and Gushikem Y 2008 J. Electroanal. Chem. $\mathbf{6 1 7} 45$

14. Yang M H, Jiang J H, Yang Y H, Chen X H, Shen G L and Yu R Q 2006 Biosens. Bioelectron. 211791

15. Shen J F, Hu Y Z, Li C, Qin C and Ye M X 2008 Electrochim. Acta $\mathbf{5 5} 4217$

16. Adekunlea A S, Pillaya J and Ozoemena K I 2010 Electrochim. Acta $\mathbf{5 5} 4319$

17. Ueda Y, Kikuchi N, Ikeda S and Houga T 1999 J. Magn. Mater. 198740

18. Monk P M S and Ayub S 1997 Solid State Ion. 99115

19. Barrera E, Gonzales I and Viveros T 1998 Sol. Energy Mater. Sol. Cells $\mathbf{5 1} 69$

20. Casella I G and Guascito M R 1999 Electrochim. Acta 451113 
21. Houshmand M, Jabbari A, Heli H, Hajjizadeh M and Moosavi Movahedi A A 2008 J. Solid State Electrochem. 121117

22. Fu C P, Zhou H H, Peng W C, Chen J H and Kuang Y F 2008 Electrochem. Commun. 10806

23. Xu C W, Wang H, Shen P K and Jiang S P 2007 Adv. Mater. 19 4256

24. Hanzu I, Djenizian T, Ortiz G F and Knauth P 2009 J. Phys. Chem. C 11320568

25. Fazle Kibria A K M and Tarafdar S A 2002 Int. J. Hydrogen Energy 27879

26. Lyons M E G and Brandon M P 2008a Int. J. Electrochem. Sci. 31386

27. Lyons M E G and Brandon M P 2010 J. Electroanal. Chem. 641119

28. Hamdani M, Singh R N and Chartier P 2010 Int. J. Electrochem. Sci. 5556

29. Lyons M E G and Brandon M P 2008b Int. J. Electrochem. Sci. 31425
30. Laouini E, Hamdani M, Pereira M I S, Berghoute Y, Douch J, Mendonça M H and Singh R N 2009 Int. J. Electrochem. Sci. 41074

31. Kibria M F and Mridha M S 1996 Int. J. Hydrogen Energy 21 179

32. Kibria F and Tarafdar S A 2002 Int. J. Hydrogen Energy 27879

33. Kubisztal J and Budniok A 2008 Int. J. Hydrogen Energy 33 4488

34. Iwakura C, Honji A and Tamura H 1981 Electrochim. Acta 26 1319

35. Wang X, Luo H, Yang H, Sebastian P J and Gamboa S A 2004 Int. J. Hydrogen Energy 29967

36. Sadiek I M, Mohammad A M, El-Shakre M E and El-Deab M S 2012a Int. J. Hydrogen Energy 3768

37. Sadiek I M, Mohammad A M, El-Shakre M E, Awad M I, El-Deab M S and El-Anadouli B E 2012b Int. J. Electrochem. Sci. 73350

38. Laviron E 1979 J. Electroanal. Chem. 100263 